\title{
DISCURSOS DE GÊNERO NA PUBLICIDADE: ANÁLISE CRÍTICA DE TEXTOS PUBLICITÁRIOS EM REVISTAS ${ }^{1}$
}

\author{
GENDER DISCOURSES IN ADVERTISING: CRITICAL ANALYSIS \\ OF ADVERTISING TEXTS IN MAGAZINES
}

GraZiela Frainer KNOLL ${ }^{2}$

Recebido em: 15/04/2011

Aprovado em: 03/02/2012

\section{RESUMO}

Este trabalho aborda a construção discursiva do gênero na publicidade. Nosso objetivo será analisar as relações de gênero em anúncios publicados em revistas, verificando as feminilidades em relação às masculinidades. Assim, os fundamentos teóricos e metodológicos da pesquisa envolvem os conceitos de gênero propostos por Scott (1995) e Bourdieu (2005), o modelo de análise crítica de discurso em três níveis (prática social, prática discursiva e texto) segundo Fairclough (2001) e o signo ideológico segundo Bakhtin/ Voloshinov (1979). O estudo da linguagem demonstra assimetrias de gênero e ocorrência de estereótipos que ainda persistem no contexto social.

Palavras-chave: Gênero; Publicidade; Análise crítica do discurso.

\section{Introdução}

Com sua origem situada a partir dos movimentos sociais dos anos $60 \mathrm{e}$ 70 , os estudos de gênero têm atraído frequentemente a atenção de pesquisas de múltiplas áreas. Considerando que o discurso é um "local" privilegiado para a disputa hegemônica, e que as relações sociais estão cada vez mais mediadas e midiatizadas, é importante analisarmos os discursos de gênero que circulam na mídia, especificamente na publicidade.

A motivação desta pesquisa advém da constatação prévia de que a publicidade utiliza diferentes recursos de linguagem nas identificações com

\begin{abstract}
This work explores the discursive construction of gender in advertising. Our aim will be to analyze gender relations in advertisements published in magazines in order to examine feminineness in relation to masculineness. Thus, the theoretical and methodological foundations involve the concepts of gender proposed by Scott (1995) and Bourdieu (2005), the critical discourse analysis model in three levels (social practice discursive practice and text) according to Fairclough (2001) and the ideological sign according to Bakhtin/Voloshinov (1979). The study of language demonstrates gender asymmetries and the occurrence of stereotypes that still persist in social context.
\end{abstract}

Keywords: Gender; Advertising; Critical discourse analysis.

os gêneros feminino e masculino. Assim, o objetivo do trabalho consiste na análise das construções de gênero na publicidade impressa através da análise crítica do discurso (ACD), descrevendo significações linguísticas e imagéticas que favoreçam a reflexão de seus efeitos sobre os discursos de gênero e sobre a sociedade.

Atualmente, muitas pesquisas no campo dos estudos de identidade têm se focado nas relações intragênero, em que são analisadas as marcas identitárias (como diferenças relacionadas à cor, à classe e à idade) somente de representações femininas ou somente de representações masculinas, verificando

${ }^{1}$ Esta pesquisa integra dissertação de mestrado da autora, intitulada Relações de Gênero na Publicidade: palavras e imagens constituindo identidades, já defendida. Pesquisa com apoio CAPES.

${ }^{2}$ Graduada em Comunicação Social, Publicidade e Propaganda pela Universidade Federal de Santa Maria (UFSM). Mestre em Letras, Estudos Linguísticos e doutoranda na mesma área pela UFSM, Brasil. E-mail: grazifk@yahoo.com.br. 
as formas hegemônicas que se manifestam em uma ou em outra. Entretanto, no Brasil, apesar de os estudos de gênero se desenvolverem já há algumas décadas e do constante esforço, por parte dos grupos acadêmicos, em acompanhar as tendências em voga, ainda é necessário e pertinente que estudemos as relações intergênero, pois os debates sobre a questão não chegaram a transpor os bancos acadêmicos como poderiam, a ponto de se concretizarem transformações realmente significativas nas práticas sociodiscursivas.

Tendo isso em vista, selecionamos, para o presente artigo, dois anúncios veiculados em revista. Como critérios de seleção, buscamos examinar duas peças veiculadas na mesma mídia, a revista Veja, cujo público é misto, ou seja, composto por mulheres e homens, e cujas imagens compõem representações humanas. Dessa forma, selecionamos anúncios referentes à mesma campanha e ao mesmo produto, porém, um contendo representação feminina e outro contendo representação masculina, ambos veiculados em diferentes edições da revista semanal ${ }^{3}$.

O embasamento teórico-metodológico abrange as teorias de gênero de Scott (1995) e Bourdieu (2005), bem como o conceito tridimensional de discurso da ACD segundo Fairclough (2001) e o signo ideológico de Bakhtin/ Voloshinov (1979).

Partimos do pressuposto de que o gênero deriva de práticas de significação, sendo a linguagem constitutiva das identidades e dos sujeitos. Trata-se, então, de um estudo cuja relevância é transdisciplinar, pois agrega assuntos que interessam à Publicidade, à Linguística e às Ciências Sociais e Humanas em geral, considerando-se que seu foco centra-se no gênero e no papel exercido pelo discurso na produção, reprodução ou transformação social.

${ }^{3}$ A pesquisa foi realizada com um corpus de dez anúncios. No presente artigo, abordamos a análise de duas dessas peças.

\section{0 conceito de gênero}

Trazendo à luz as distinções e desigualdades que compõem as feminilidades e masculinidades e revelando toda a complexidade das relações sociais, o conceito de gênero surgiu como produto das teorias feministas. Os movimentos feministas remontam a várias épocas e lugares: à França do século XVIII, durante a Revolução Francesa, em que Olympe de Gouges escreveu a Declaração dos Direitos das Mulheres e da Cidadã (1791), argumentando que os direitos dos homens também pertenciam às mulheres; aos Estados Unidos do século XIX, com o primeiro movimento oficialmente organizado; à Inglaterra de 1919, com a grande mobilização das sufragistas inglesas. Contudo, foi nos anos 60 e 70 que eclodiram os movimentos mais expressivos nos Estados Unidos, na Inglaterra e na França, que, mais tarde, espalharam-se pelo mundo ${ }^{4}$.

Para tanto, foi fundamental a presença de jornalistas e escritoras a favor da causa nos meios de comunicação. Livros como O Segundo Sexo (1947), da francesa Simone de Beauvoir, Um teto todo seu (1929), de Virginia Woolf, e a Mistica Feminina (1963), da norte-americana Betty Friedan, além de revistas como Ms Magazine (1972), serviram de inspiração e referência, ajudando a congregar mulheres ao movimento.

$\mathrm{O}$ movimento segmentou-se em várias vertentes e com as mais diversas reivindicações: desde grupos que lutam pelo fim da hierarquização entre os sexos, até grupos que defendem a supremacia feminina como forma de igualdade, ou que lutam pelo direito ao aborto e pelos direitos homossexuais. Contudo, a unidade central do feminismo pode ser definida como a proposta política de dis-

${ }^{4}$ Os debates feministas foram extremamente intensos entre 1968 e 1969 quando surgiu o feminismo radical de Nova York. No Brasil, o movimento feminista difundiu-se principalmente a partir de 1975. Apesar de ter alcançado muitas partes do mundo, em maior ou menor intensidade, o movimento pouco atingiu os países orientais islâmicos ou parte do continente africano (localidades em que prevalecem costumes tribais). Nesses locais, a opressão às mulheres ainda é mais forte que a garantia de seus direitos. 
cussão da condição feminina e, sobretudo, a contestação ao patriarcalismo.

O que está em jogo é uma tentativa de reconstrução da identidade feminina, o que é corroborado por Castells (1999, p. 237), segundo o qual o objetivo subjacente a todo o movimento consiste em "desconstruir a identidade feminina, destituindo as instituições sociais das marcas de gênero".

Durante esse processo de repensar as condições sociais das mulheres, foram geradas muitas elaborações teóricas, dentre elas, a concepção de gênero como categoria de análise sócio-histórica. A partir do trabalho fundador de Scott (1995) - publicado nos Estados Unidos em 1986, na França em 1988, e pela primeira vez no Brasil em 1990 -, a teoria dos gêneros privilegiou o enfoque da condição de mulheres e homens no contexto de relações de poder, aproximando-nos, assim, da realidade da ordem social. Desse modo, foi destacado que gênero é categoria relacional, ou seja, abrange as relações sociais entre o feminino e o masculino, de forma que um gênero só adquire sentido em relação ao outro.

Seguindo a mesma linha, Bourdieu (2005, p.34) afirma que "tendo apenas uma existência relacional, cada um dos dois gêneros é produto do trabalho de construção diacrítica, ao mesmo tempo teórica e prática que é necessário à sua produção como corpo socialmente diferenciado do gênero oposto".

A utilização do gênero como referência às diferenças socialmente construídas levou ao entendimento de que as distinções entre o feminino e o masculino não são fatos naturais, pelo contrário, são forjadas pelos indivíduos em sociedade e perpassadas pela cultura. São naturais as diferenças corporais ou biológicas, por exemplo, é natural o fato de que as mulheres tenham os filhos, mas é sociocultural o fato de que elas e somente elas sejam encarregadas de cuidá-los ou educá-los. Isso significa que a desigualdade entre os sexos, no que diz respeito à divisão das atividades humanas em geral, não pode ser justificada pelo argumento das especificidades biológicas.

Como explica Colling:

A história do gender das norte-americanas, do genre francês, do genere italiano, do geschlecht alemão, e do gênero português, tem um só objetivo: introduzir na história global a dimensão da relação entre os sexos, com a certeza de que esta relação não é um fato natural, mas uma relação social construída e incessantemente remodelada, efeito e motor da dinâmica social (COLLING, 2004, p. 28).

Então, a categoria gênero surgiu para se contrapor ao apelo biológico do sexo devido à necessidade de um outro conceito que englobasse os fatores sociais que compunham a questão. No debate sobre as disparidades entre homens e mulheres, o argumento biológico funciona como uma armadilha, pois é algo que não podemos mudar, colaborando para a naturalização das desigualdades e fazendo a questão parecer irreversível.

De acordo com Paulson (2002, p. 32 ), o conceito provocou o questionamento da "ideologia do determinismo biológico que vê uma relação de causalidade direta entre sexo e gênero, e também ultrapassar a negação de toda relação entre esses fatores tão comuns no discurso acadêmico sobre o gênero".

Pereira (2004, p. 195) considera que o gênero trouxe importantes contribuições à produção do conhecimento, iniciando pela ruptura com o determinismo biológico e instituindo uma definição sociocultural, conforme explicamos anteriormente. Além disso, outras contribuições são apontadas pela autora:

- O gênero pode ser utilizado como categoria analítica sob diversas perspectivas disciplinares;

- O gênero reforça a corrente não essencialista dos estudos de identidade;

- O gênero redefiniu processos de 
subjetividade e identidade e favoreceu o estudo de outras construções sociais a ele vinculadas, como etnia, idade e classe.

Denominam-se discursos de gênero os discursos que instituem as relações sociais e as diferenças entre os sexos, o que é feito através de construções simbólicas que determinam e mantêm o status quo, atribuindo papéis a um ou outro gênero, ou seja, envolve o conjunto de expectativas sociais e padrões de comportamento. Portanto, os discursos de gênero variam de acordo com o contexto social, cultural e histórico.

Segundo Marodin:

O papel do gênero é, então, o conjunto de expectativa em relação aos comportamentos sociais que se esperam das pessoas de determinado sexo. A estrutura social é que prescreve uma série de funções para o homem e para a mulher, como próprias ou "naturais" de seus respectivos gêneros. Essas diferem de acordo com as culturas, as classes sociais e os períodos da história (MARODIN, 1997, p. 10).

Atualmente, se tomarmos como exemplo a sociedade ocidental, ainda que um número cada vez maior de mulheres estude e exerça trabalho remunerado, as diferenças e desigualdades entre os gêneros se refletem nos cargos e hierarquias no ambiente de trabalho. Isso é comprovado por Cortazzo e Schettini (2004, p. 83), que constataram que, frequentemente na América Lati$\mathrm{na}^{5}$, a maioria das mulheres que trabalha fora de casa ocupa posições inferiores aos homens ou cargos temporários.

Os discursos de gênero evoluíram ao longo dos anos, de forma que pelo menos parte dos antigos modelos de comportamento passou a coexistir com as transformações sociais e os novos modelos emergentes. Desse modo, é comum observarmos um acúmulo de papéis e funções, como mulheres que se dedicam a suas carreiras sem, contudo,

${ }^{5}$ As pesquisadoras utilizaram dados de pesquisas públicas de Brasil, Argentina e México. deixarem de ser donas-de-casa ou principais educadoras dos filhos. Sobre esse aspecto, Confortin (2003) considera que, ao mesmo tempo em que há uma multiplicidade de funções passíveis de serem realizadas pelas mulheres (donasde-casa, esposas e profissionais remuneradas), há a desvalorização dos papéis desempenhados e da própria mulher.

Bourdieu (2005) estabelece três princípios práticos sobre a divisão do trabalho que asseguram a permanência de antigas estruturas de dominação. Em primeiro lugar, as profissões pelas quais as mulheres, geralmente, optam estão relacionadas ao cuidado de crianças, doentes, casas ou pessoas, ou seja, situam-se no prolongamento das funções domésticas, como ensino (professoras, educadoras, babás), saúde (enfermeiras, nutricionistas, médicas) e serviços (faxineiras, cozinheiras). Em segundo, há o pensamento conforme o qual uma mulher "não pode" exercer autoridade sobre homens, de maneira que ainda é raro vê-la na posição de comando de um grupo de trabalho, é mais frequente que ela preencha um cargo subordinado ou auxiliar a um homem ou grupo de trabalho (assistente; secretária). E, em terceiro, o monopólio da manutenção das máquinas e dos objetos técnicos de trabalho permanece, majoritariamente, nas mãos dos homens, mantendo, assim, a produção de bens em seu poder.

Salientamos que tudo isso é produto de criações sociais enraizadas nas práticas culturais. Nada impede mulheres de exercerem qualquer atividade braçal ou intelectual, nem homens de exercerem trabalho doméstico, exceto padrões de comportamento culturalmente produzidos e transmitidos na esfera social. E esses padrões de conduta distintos para homens e mulheres começam a se formar na menor unidade social, a família, e continuam sendo reproduzidos, reafirmados e/ou subvertidos em outros meios, como a mídia e a publicidade. 


\section{Gênero na publicidade}

Dentre as diversas práticas sociais, a comunicação midiática, especificamente a publicidade, atua sobre a produção, manutenção e/ou transformação dos discursos de gênero. Para compreendermos isso, precisamos considerar que a publicidade atua entre dois pólos: a produção e o consumo. Do ponto de vista do consumidor, o produto a ser consumido possui não só um valor de troca ou uso, mas um valor simbólico. Devido a esse valor simbólico, as pessoas buscam, no consumo, o suprimento de demandas psicossociais que envolvem sentimentos como autoestima, status, evolução pessoal e conquista (MASLOW, 1984).

São essas motivações psicossociais que explicam por que certos anúncios e representações atraem a atenção de determinada pessoa e não de outra. Isso ocorre devido ao fato de as pessoas buscarem, no consumo, muito mais do que apenas a supressão da carência de um produto. Elas buscam a supressão de carências de projeção social, estilo de vida, realização pessoal e, sobretudo, de identidade.

Conforme Vestergaard e SchrØder:

os anúncios devem preencher a carência de identidade de cada leitor, a necessidade que cada pessoa tem de aderir a valores e estilos de vida que confirmem seus próprios valores e estilos de vida e lhe permitam compreender o mundo e seu lugar nele (VESTERGAARD e SCHRØDER, 2000, p. 74).

Dessa forma, como afirmam os autores, a publicidade constitui um processo de significação em que a carência de identidade se transforma na carência do produto. O que faz com que uma pessoa opte por consumir um produto de determinada marca e não outro equivalente de outra marca é toda a carga simbólica que o acompanha, ou seja, depende da relação estabelecida pelo texto entre anunciante e leitor através de representações discursivas e imagéticas.

A mídia tem o poder de representar, e, conforme observa Silva (2000, p. 91), "quem tem o poder de representar tem o poder de definir e determinar a identidade". À medida que associam significados, imagens, características, condutas e estilos de vida a um ou outro gênero, as representações midiáticas ajudam a configurar identidades e relações de poder na sociedade.

Entretanto, apesar do poder exercido pelos discursos da mídia na sociedade contemporânea, a produção de sentidos não garante a assimilação ${ }^{6}$ de modelos de comportamento e papéis de gênero pelos sujeitos interpelados. A subjetividade é inerente à linguagem e, com isso, existe o potencial de aceitação ou de rompimento dos sentidos articulados no discurso, em um contexto de comunicação.

\section{Linguagem e sociedade no foco da ACD}

Levar em consideração o potencial de transformação lado a lado com a produção ou reprodução das relações sociais é um dos diferencias da análise crítica do discurso (ACD). A partir da dialética entre estrutura e ação, ao mesmo tempo em que há uma estrutura de perpetuação da ideologia dominante, há também uma relativa liberdade do sujeito que, mesmo engajado em práticas sociais que operam na manutenção da ordem vigente, tem a possibilidade de transformação social.

Os indivíduos tornam-se sujeitos e constroem o mundo social por meio de práticas de significação, ou seja, por meio da linguagem. Isso significa que questões de linguagem são questões sociais, e vice-versa, pois linguagem e sociedade estão em uma relação constitutiva infindável, o que corresponde

\footnotetext{
Entendemos por assimilação o "processo social em virtude do qua indivíduos e grupos diferentes aceitam e adquirem padrões comportamentais, tradição, sentimentos, e atitudes da outra parte" (LAKATOS e MARCONI, 1999, p. 343)
} 
ao foco primordial da análise crítica do discurso. Ao contrário de teorias lingüísticas com foco restrito na análise textual ou nos aspectos cognitivos da linguagem, a ACD visa a integrar o estudo da linguagem com uma teoria sociológica, propondo um modelo de análise dos processos sociais e culturais atrelados ao discurso.

Com isso, consideramos o papel da linguagem na produção, manutenção e/ou transformação de aspectos socioculturais, de modo que a linguagem não é de forma alguma transparente ou mero reflexo da sociedade. Fairclough (2001) define a relação entre linguagem e sociedade como interna e dialética, o que significa que, ao mesmo tempo em que é moldado pela estrutura social, o discurso é constitutivo dessa mesma estrutura.

Não existe linguagem fora do mundo, tampouco mundo fora da linguagem, uma vez que esta se faz presente em todas as ações humanas. Portanto, fenômenos linguísticos são sociais, bem como fenômenos sociais são lingüísticos (FAIRCLOUGH, 1989; 2001).

Entender o discurso como prática social significa concebê-lo como todo o processo de interação do qual o texto é somente uma parte, desse modo, o discurso é um processo, e o texto é o produto dessa interação, a materialidade linguística ou imagética decorrente desse processo. $\mathrm{O}$ discurso é simultaneamente um modo de representação, significação e ação: representação de mundo, construção do mundo em significado e ação das pessoas sobre o mundo e sobre outras pessoas.

O discurso contribui para a constituição de todas as dimensões da estrutura social que, direta ou indiretamente, o moldam e o restringem: suas próprias normas e convenções, como também relações, identidades e instituições que lhe são subjacentes. O discurso é uma prática, não apenas de representação do mundo, mas de significação do mundo, constituindo e construindo o mundo em significado (FAIRCLOUGH, 2001, p. 91).
Com base na proposta do autor elaborada em Language and Power (1989) e, posteriormente, desenvolvida em Discurso e Mudança Social (1992; 2001), identificamos dois tipos de efeitos: efeitos do discurso sobre a sociedade e efeitos da sociedade sobre o discurso.

No primeiro grupo, dos efeitos construtivos do discurso, temos o seguinte:

- O discurso contribui para a construção de identidades sociais e posições de sujeito, pois é no discurso que percebemos o mundo e nossa existência nele;

- O discurso contribui para a construção das relações sociais, que são representadas e negociadas no discurso, processo de interação social;

- O discurso contribui para a construção de sistemas de conhecimento, pois é um modo de significação do mundo e de seus processos, entidades e relações.

No segundo grupo, dos efeitos da sociedade sobre o discurso, temos que o discurso é investido de ideologias, moldado por orientações econômicas, políticas e culturais, determinado pelo contexto que o constitui, moldado pelas relações sociais (contribui para a sua construção, mas, ao mesmo tempo, é constituído por tais relações) e determinado por redes de poder que levam à legitimação de certos discursos, em detrimento de outros.

Falando em estruturas sociais que moldam, condicionam e determinam o discurso, é importante ressalvarmos que a prática discursiva é constitutiva tanto de maneira convencional como criativa, ou seja, contribui para reproduzir a sociedade, como também para transformá-la (FAIRCLOUGH, 2001). Por esse motivo, o autor relaciona discurso e mudança social, devido à capacidade de criação e transformação de estruturas sociais por meio da linguagem ou do discurso.

Ao defender uma dialética entre sociedade e linguagem que prevê uma dupla via entre estrutura e ação, a ACD 
diverge do ponto de vista de Althusser (1991), segundo o qual as condições reais de existência e a liberdade dos sujeitos seriam restringidas por instituições que assegurariam a reprodução da ideologia dominante das relações de produção e dominação existentes na sociedade. Para a ACD, ao invés de indivíduos "assujeitados", existem agentes sociais dotados de potencial criativo, e o poder de transformação encontra-se no discurso e nas demais práticas sociais.

No estudo do vínculo entre ideologia e linguagem, a ACD recorre a Bakhtin/Voloshinov (1979), que situa a ideologia no nível do signo linguístico: todo signo é ideológico, de forma que a língua não pode ser dissociada dos conteúdos ideológicos que veicula.

Um produto ideológico faz parte de uma realidade (natural ou social) como todo corpo físico, instrumento de produção ou produto de consumo; mas, ao contrário destes, ele também reflete e refrata uma outra realidade, que lhe é exterior. Tudo que é ideológico possui um significado e remete a algo situado fora de si mesmo. Em outros termos, tudo que é ideológico é um signo. Sem signos não existe ideologia (BAKHTIN/VOLOSHINOV, 1979, p. 17).

$\mathrm{Na}$ perspectiva dialógica de Bakhtin (1979), a ideologia está inserida no quadro da constituição dos signos e da subjetividade. Dessa forma, o signo linguístico constitui-se por uma dupla materialidade (é uma unidade físico -material e uma unidade sócio-histórica) e por um conteúdo ideológico, isto é, uma interpretação da realidade social.

Na realidade, não são palavras o que pronunciamos ou escutamos, mas verdades ou mentiras, coisas boas ou más, importantes ou triviais, agradáveis ou desagradáveis, etc. A palavra está sempre carregada de um conteúdo ou de um sentido ideológico ou vivencial. É assim que compreende- mos as palavras e somente reagimos àquelas que despertam em nós ressonâncias ideológicas ou concernentes à vida (BAKHTIN/VOLOSHINOV, 1979, p. 95).

Devido ao fato de o discurso ser visto por um ângulo de contextualização histórica, em que as ideologias e as práticas sociais que o constituem são trazidas à discussão, a análise crítica propicia o entendimento de fenômenos socioculturais e assimetrias de poder, desnaturalizando estruturas de dominação e evidenciando que os dados são, na verdade, construídos. Wodak (2004, p. 226) explica que os estudos nesse campo "se voltam especificamente para os discursos institucional, político, de gênero social, e da mídia (no sentido mais amplo), que materializam relações mais ou menos explícitas de luta e conflito".

Conforme Fairclough:

A análise de um discurso particular como exemplo de prática discursiva focaliza os processos de produção, distribuição e consumo textual. Todos esses processos são sociais e exigem referência aos ambientes econômicos, políticos e institucionais particulares nos quais o discurso é gerado (FAIRCLOUGH, 2001, p. 99).

Em diferentes contextos, sob formas de produção e consumo específicas, discursos distintos se materializam. Assim, considerando a dupla via entre discurso e estruturas sociais, o contexto torna-se parte integrante do texto. O contexto abrange as situações em que ocorrem os eventos discursivos, o meio de circulação e consumo dos textos, a forma em que se dá a interação, os papéis dos interlocutores na comunicação, além de orientações culturais mais amplas.

Por isso, consideramos a concepção de discurso como tridimensional: os discursos são constituídos por três

\footnotetext{
$\mathrm{O}$ autor ressalva que a prática discursiva tem natureza parcialmente sociocognitiva, pois produção e interpretação resultam de processos cognitivos e são baseadas em convenções sociais internalizadas.
} 
dimensões interligadas, a saber, texto, prática discursiva e prática social. $\mathrm{O}$ texto é a materialidade discursiva e compreende textos linguísticos e imagéticos; a prática discursiva envolve a interação entre as condições de produção, a distribuição e o consumo dos textos; e a prática social corresponde ao contexto que circunda a realização discursiva, ou seja, aos aspectos extralinguísticos, como orientações políticas, econômicas, culturais e ideológicas. Todavia, Chouliaraki e Fairclough (1999) explicam que não é necessário seguir, rigorosamente, uma sequência ou separação em três níveis. As três dimensões podem estar dispersas ou pulverizadas na análise.

\section{Os anúncios analisados}

As análises seguem o modelo proposto por Fairclough (2001), segundo o qual o discurso possui uma dimensão social (a prática social) e uma dimensão material (o texto), sendo ambas as dimensões mediadas por uma terceira, a prática discursiva. Conforme dissemos anteriormente, a análise não segue uma sequência ou separação rigorosa em três níveis, de forma que as partes que integram o discurso podem estar dispersas, desde que sejam contempladas. Em resumo, o texto é a materialidade discursiva, a prática discursiva são as condições de produção, a distribuição e o consumo dos textos, e a prática social corresponde ao contexto que circunda a realização discursiva, as orientações culturais e ideológicas que constituem o contexto.

A análise abrange dois anúncios publicitários impressos, veiculados na revista Veja, publicação semanal de maior circulação do Brasil, composta por textos, como reportagens, entrevistas, artigos de opinião, além de anúncios publicitários. Os assuntos abordados na revista consistem em atualidades do país e do mundo em áreas variadas, como política, economia, ciência, cultura, artes, esportes. Todos os textos constituintes da revista, inclusive os publicitários, são elaborados tendo em vista o perfil geral do público leitor. Isso significa que os anúncios são produzidos com foco no público que lê a revista.

De acordo com dados da editora $\mathrm{Abril}^{8}$, a revista tem público misto (53\% dos leitores são mulheres, 47\%, homens), com idade predominante nas faixas de 25 a 34 anos $(22 \%), 35$ a 44 $(21 \%)$ e acima de 50 anos $(22 \%)$, pertencente às classes sócio-econômicas $\mathrm{A}$ (28\%), B (46\%), C (23\%) e D (3\%). Os anunciantes principais são marcas bancárias, telefônicas, marcas de automóveis, jóias, cigarros, bebidas, etc.

Na publicidade, a linguagem tem papel constitutivo, ou seja, é o que estabelece a comunicação entre o anunciante e o leitor/consumidor potencial. Nesse caso, como se trata de publicidade veiculada em mídia impressa, podemos considerar a situação de comunicação nos termos de Thompson (2005), como uma "quase-interação mediada". Nessa situação, a mensagem se destina de um autor para um grande número de leitores não identificáveis, e o contato se estabelece exclusivamente por meio do texto. Devido ao fato de a linguagem ser persuasiva, Fairclough (2001, p. 259) define o discurso publicitário como "estratégico".

Dessa forma, os modos de representação de mundo na publicidade são construídos levando-se em conta o objetivo principal da prática: fazer vender, estimular o consumo. Isso significa que as pessoas e as situações representadas nas peças visam estabelecer uma identificação com o leitor, fazendo com que a busca por uma identidade se traduza no consumo.

Ambos os anúncios do celular Siemens Mobile foram veiculados em página dupla na revista Veja, edições 1.805 e 1.806 , de 04 e 11 de

\footnotetext{
${ }^{8}$ Informações disponibilizadas pela editora em 2010, no site:
} http://publiabril.com.br/. Pesquisa Marplan com base no ano 2009. 
junho de 2003, respectivamente. O primeiro anúncio (Figura 1) contém a ilustração de uma mulher em um galinheiro, em meio a várias galinhas, segurando o celular em direção ao bico de uma delas. Há também a foto de um celular em close e o seguinte texto:

\section{Fui gravar o toque do meu "ex" e já} volto.

2. Novo Siemens C55

3. Só ele grava qualquer som para personalizar o toque de quem ligar. E mais: sons polifônicos, troca de mensagens com sons e figuras, Internet em alta velocidade e capinhas que brilham no escuro. Siemens C55. Grave esse modelo.

4. Viva a inspiração.

O sujeito de "fui gravar" e "já volto" é o pronome pessoal "eu" implícito, que, pela combinação ente os códigos semióticos, corresponde a um sujeito feminino. No texto verbal, selecionamos, para fins de análise, a palavra "ex". Esse "ex" que o enunciador menciona consiste em um participante mas- culino (a julgar pela expressão "do meu "ex"”, assim como pela denominação do "ex" como "Cadu" no visor do celular), podendo, desse modo, ser compreendido como ex-namorado, ex-marido ou ex-companheiro.

$\mathrm{Na}$ imagem, verificamos uma mulher que grava o cacarejo de uma galinha no galinheiro, e, no visor do celular, o ícone de duas galinhas associadas ao nome "Cadu". Detectamos assim a metáfora implícita de que "Cadu é galinha", ou o "'ex' é galinha". No sentido conotativo, é chamada de galinha a pessoa volúvel, que não se contenta com um único parceiro, podendo também significar pessoa medrosa, covarde ou fraca (FERREIRA 1999, p. 964). O significado de galinha nesse uso linguístico específico tem sentido pejorativo, tom de crítica, ofensa, deboche, brincadeira ou de uma pequena vingança: cada vez que Cadu ligar, ela ouvirá o cacarejo que associou ao "ex" no toque e no ícone do celular.

Portanto, a mulher está representada desempenhando uma ação que faz alusão ao mexerico, culturalmen-

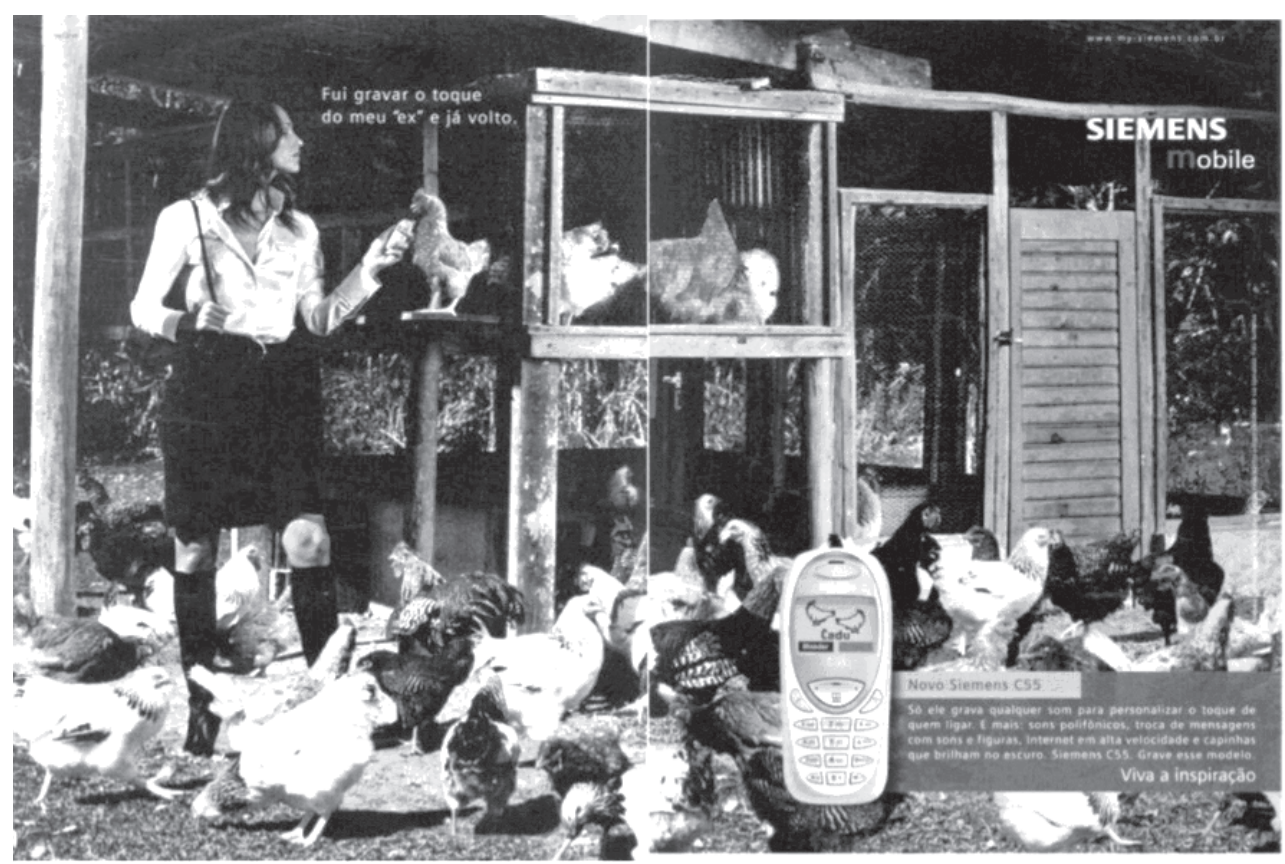

Figura 1 - Anúncio 1, representação feminina. 
te entendido como uma solidariedade feminina de falar mal do "ex" para as amigas, de compartilhar com elas os defeitos do "ex". Conforme afirmam Vertergaard e Schroeder (2000, p. 99), "é muito comum pensar que o mexerico é coisa de mulheres", e isso é reforçado nessa peça publicitária.

$\mathrm{O}$ segundo anúncio (Figura 2) tem como ilustração um homem em um cenário que parece ser uma selva, deitado sobre um tronco de árvore, esticando a mão em direção a um tigre, o qual está deitado com a boca aberta em direção ao homem como se estivesse rugindo (com a onomatopéia "GRRRR"). À esquerda da peça, há a foto de celular em close e o texto:

\section{Fui gravar o toque do meu chefe e já} volto.

2. Novo Siemens C55

3. Só ele grava qualquer som para personalizar o toque de quem ligar. E mais: sons polifônicos, troca de mensagens com sons e figuras, Internet em alta velocidade e capinhas que brilham no escuro. Siemens C55. Grave esse modelo.

4. Viva a inspiração.

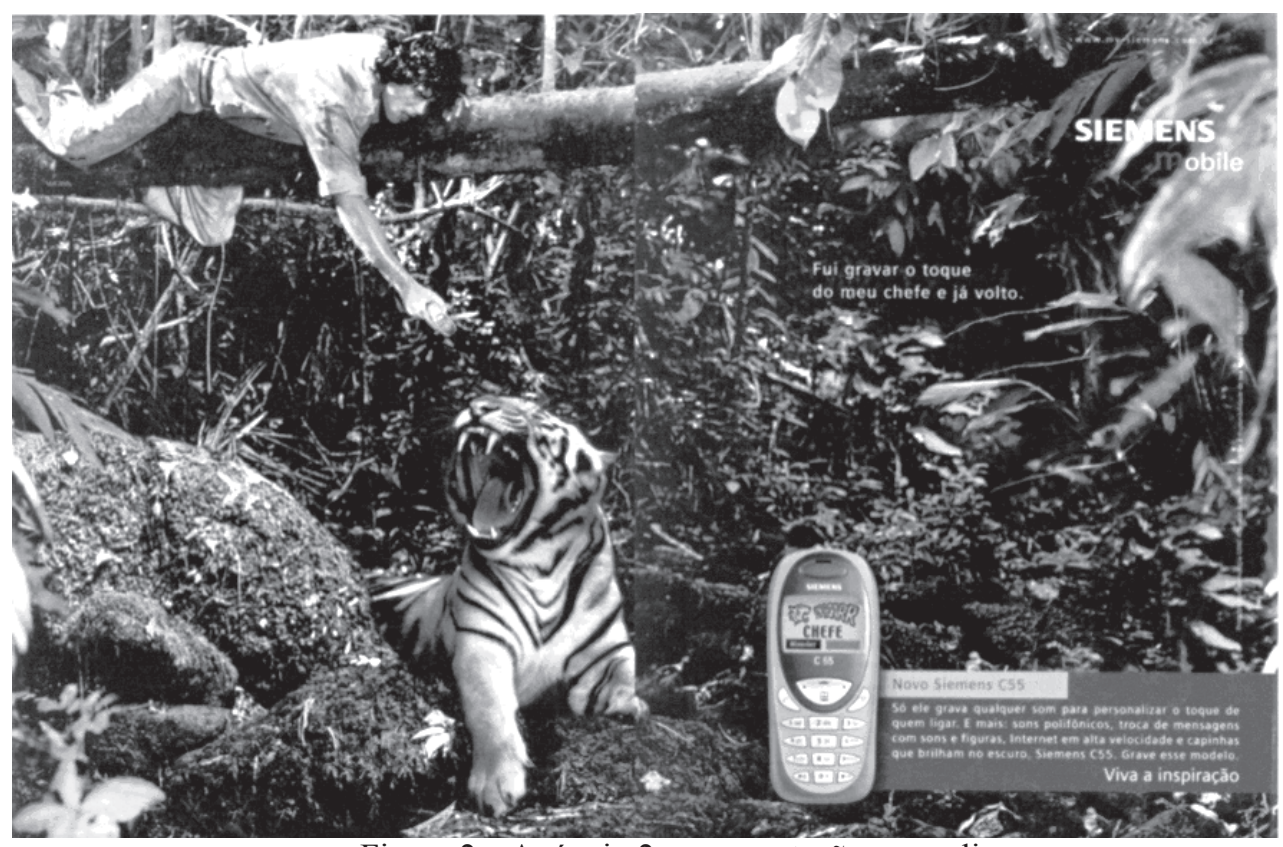

Figura 2 - Anúncio 2, representação masculina.

Verificamos que há um "eu" masculino, sujeito implícito de "fui gravar" e "já volto". Isso significa que existem, no texto, dois participantes masculinos: o "eu" implícito, que sabemos ser um homem devido à imagem presente no anúncio, e o "chefe", que percebemos ser homem pelo uso do pronome possessivo masculino "meu".

Analisamos a palavra "chefe", cujo sentido no contexto de uso somente pode ser compreendido ao lermos a imagem em conjunto com o enunciado verbal. Na imagem, observamos que o sujeito masculino foi gravar o toque do chefe na selva, e que esse toque corresponde ao rugido de um tigre, o que é reafirmado na imagem do visor do celular, onde há um tigre como ícone e a identificação "chefe". Consideramos que essa combinação do texto verbal com a imagem também produz uma metáfora implícita, pois o sujeito da oração afirma, através da ação representada, que seu chefe é um tigre.

No sentido figurado, é chamado de tigre o homem sanguinário, bárbaro e cruel, conforme a definição encontrada no dicionário (FERREIRA, 1999, p.1958). Sendo assim, compreendemos 
que, segundo o ponto de vista do sujeito do enunciado, o chefe é bravo como um tigre, zanga-se facilmente, é assustador, provoca medo.

Apesar de o sentimento de medo, aversão ou antipatia de um funcionário em relação a seu chefe ser comumente manifestado, tanto por homens, quanto por mulheres, percebemos que o substantivo "chefe" aparece no anúncio cuja representação é masculina. Isso provavelmente ocorre porque a identificação do homem com o campo de atuação profissional, e a identificação das mulheres com assuntos afetivos sejam formas que fazem parte do imaginário coletivo, culturalmente produzido e reproduzido. Da mesma forma que o chefe referido também é um homem.

O termo "galinha", referente ao anúncio anterior, pode ser aplicado como ofensa tanto a homens, quanto a mulheres. No entanto, ele foi utilizado especificamente no texto cujo sujeito representado é uma mulher, e cujo indivíduo considerado "galinha" é homem. Partindo do pressuposto de nosso trabalho, de que o signo é ideológico e de que as construções discursivas estão ligadas a um contexto de produção e recepção, jamais ocorrendo de maneira arbitrária, uma provável justificativa para essas diferenças observadas em ambos os anúncios provém dos discursos de gênero circulantes na sociedade.

Ao longo dos tempos, o pensamento racional tem sido associado aos homens, enquanto que a emoção é associada às mulheres, uma crença cultural que, mesmo nos dias atuais, persiste. Assim, ainda que gravar o rugido de um tigre seja expressar um sentimento em relação ao chefe, chamar de galinha alguém com quem se teve um relacionamento pessoal é uma atitude muito mais afetiva ou emocional que uma provocação do ambiente de trabalho.

Nas imagens de ambos os anúncios, também verificamos distinções. A mulher representada está em uma pose que pode ser considerada como normal para o espaço urbano, trajada para andar em uma cidade. Já o homem representado no anúncio seguinte, saiu da normalidade de seu trabalho e se encontra deitado sobre um tronco de árvore, a fim de alcançar o tigre. A mulher grava o cacarejo de uma galinha, que está posicionada praticamente no seu mesmo nível de altura, enquanto que o homem inclina-se, deita-se, estica-se para alcançar sua meta, o tigre posicionado no nível do chão.

\section{Considerações finais}

Conforme visto, anúncios de um mesmo produto, que compõem a mesma campanha publicitária, constroem discursos de gênero diferentes para representações femininas e representações masculinas. Isso opera no sentido de reafirmar que mulheres e homens ocupam lugares e papéis diferentes, ou seja, reafirmar as diferenças socialmente construídas.

$\mathrm{O}$ estudo da linguagem nos textos corrobora a afirmação de Marodin (1997) de que o gênero abrange as expectativas sociais, prescrevendo papéis que diferem para os respectivos gêneros e de acordo com o momento sociocultural e histórico. Outro ponto que depreendemos das análises é a noção de gênero como categoria relacional, ou seja, que só adquire sentido nas relações sociais, conforme um se constrói em relação ao outro (SCOTT, 1995; BOURDIEU, 2005).

A concepção de discurso como prática social implica que os sujeitos agem por meio da linguagem, e que textos e estruturas sociais interagem dialeticamente. Dessa maneira, constatamos que as práticas discursivas e as práticas sociais conectam-se à medida que as construções ou os discursos de gênero são afetados ou atravessados por orientações culturais e ideológicas que circulam na esfera social.

$\mathrm{O}$ vínculo entre linguagem e so- 
ciedade é interno e dialético, portanto, o discurso faz parte da constituição de todas as dimensões da estrutura social que o moldam e restringem de uma maneira ou de outra (FAIRCLOUGH, 2001). Isso significa que o discurso contribui para a construção de identidades, para a edificação das relações sociais e pelos modos como percebemos o mundo e como agimos nele, que não são neutros ou desprovidos de valores. Afinal, "A palavra está sempre carregada de um conteúdo ou de um sentido ideológico ou vivencial" (BAKHTIN/VOLOSHINOV, 1979, p. 95).

Tendo isso em mente, apesar de os padrões estabelecidos se constituírem como efeito das relações sociais, nada impede que manifestemos outros comportamentos: mulheres e homens podem fugir das expectativas e construir suas próprias identidades e funções sociais, já que não há um "eu" feminino ou masculino absoluto ou essencial. Há, porém, a pressão do meio agindo através dos discursos, das práticas socioideológicas, do senso comum e da própria estrutura social, influenciando os sistemas de crença.

Com base nos dados obtidos pela pesquisa, os anúncios contribuem, predominantemente, para a manutenção de sistemas de crença com relação ao gênero já enraizados na sociedade, uma vez que são constantemente produzidos e reproduzidos, como a ligação do homem com o trabalho e da mulher com assuntos afetivos. As marcas identitárias construídas nos textos corroboram as diferenças socialmente percebidas entre homens e mulheres, visto que os anúncios contendo representações femininas possuem elementos verbais e visuais distintos dos anúncios contendo representações masculinas.

\section{Referências}

ALTHUSSER, Louis. Aparelhos ideológicos de Estado. 5. ed. Rio de Janeiro: Edições Graal, 1991.

BAKHTIN, Mikhail (VOLOSHINOV). Marxismo e filosofia da linguagem. São Paulo: Hucitec, 1979.

BOURDIEU, Pierre. A dominação masculina. 4. ed. Rio de janeiro: Bertrand Brasil, 2005.

CASTELLS, Manuel. O poder da identidade. A era da informação: economia, sociedade e cultura. v. 2. 3. ed. São Paulo: Paz e Terra, 1999.

CHOULIARAKI, Lilie; FAIRCLOUGH, Norman. Discourse in late modernity - Rethinking critical discourse analysis. Edinburgh: Edinburgh University Press, 1999.

COLLING, Ana. A Construção Histórica do Feminino e do Masculino. In: STREY, M. N.; CABEDA, S. T. L.; PREHN, D. R. (orgs.). Gênero e cultura: questões contemporâneas. Porto Alegre: EDIPUCRS, 2004.

CONFORTIN, Helena. Discurso e Gênero: a mulher em foco. In: GHILARDI-LUCENA, M. I. Representações do Feminino. Campinas, SP: Átomo, 2003.

CORTAZZO, Isabel; SCHETTINI, Patricia. Mujeres Pobres en la Trampa Cultural de la Política Social y Local. In: STREY, M. N.; CABEDA, S. T. L.; PREHN, D. R. (orgs.). Gênero e cultura: questões contemporâneas. Porto Alegre: EDIPUCRS, 2004. 
FAIRCLOUGH, Norman. Discurso e mudança social. Brasília: Editora UnB, 2001.

. Language and power. New York: Longman, 1989.

FERREIRA, Aurélio. Buarque de Holanda. Novo Aurélio Século XXI: o dicionário da língua portuguesa. 3. ed. Rio de Janeiro: Nova Fronteira, 1999.

LAKATOS, Eva Maria; MARCONI, Marina de Andrade. Sociologia Geral. 7. ed. São Paulo: Atlas, 1999.

MARODIN, Miriam. As relações entre o homem e a mulher na atualidade. In: STREY, M. N. (org.). Mulher, estudos de gênero. São Leopoldo: Ed. UNISINOS, 1997. p 9-18.

MASLOW, Abraham. Motivation and personality. New York: Harper \& How, 1954.

PAULSON, Susan. Sexo e gênero através das culturas. In: ADELMAN, M. E SILVESTRIN, C. B. (orgs.) Coletânea gênero plural. Curitiba: Ed. UFPR, 2002. p. 23-32.

PEREIRA, Verbena Laranjeira Gênero: dilemas de um conceito. In: STREY, M. N.; CABEDA, S. T. L.; PREHN, D. R. (orgs.). Gênero e cultura: questões contemporâneas. Porto Alegre: EDIPUCRS, 2004.

SCOTT, Joan. Gênero: uma categoria útil de análise histórica. Revista Educação \& Realidade, Porto Alegre, v. 2, n. 20, Jul/Dez, 1995.

SILVA, Tomaz Tadeu da. A produção social da identidade e da diferença. In:
SILVA, T. T. da. (org.). Identidade e Diferença: a perspectiva dos estudos culturais. Petrópolis: Vozes, 2000.

THOMPSON, John B. Ideologia e cultura moderna: Teoria social crítica na era dos meios de comunicação de massa. 4. ed. Petrópolis: Vozes, 2005.

VESTERGAARD, Torben; SCHRODER, Kim. A Linguagem da propaganda. São Paulo: Martins Fontes, 2000.

WODAK, Ruth. Do que trata a ACD um resumo de sua história, conceitos importantes e seus desenvolvimentos. Linguagem em (Dis)curso, Tubarão, v. 4, n. especial, 2004. 
